\title{
Medical Therapy for Glaucoma: The Next 20 Years
}

\section{Carol A Rasmussen, Paul L Kaufman}

Department of Ophthalmology and Visual Sciences, University of Wisconsin School of Medicine and Public Health, Madison, Wisconsin, USA

\section{INTRODUCTION}

Current medical therapy for glaucoma relies on intraocular pressure (IOP) regulation via enhancing aqueous humor outflow and/or decreasing aqueous inflow. The relationship between inflow and outflow determines IOP and may be modulated by receptors or mediators within the eye, which detect changes in IOP and trigger responses to adjust fluid balance.

Inflow via aqueous humor formation (AHF) is the result of three physiologic processes: diffusion, ultrafiltration and active secretion, which can be affected by therapies using betablockers, carbonic anhydrase inhibitors and $\alpha 2$-adrenergic agonists. Decreased blood flow can also decrease AHF.

Aqueous humor outflow occurs principally via the trabecular and the uveoscleral routes, which are targeted with cholinergics, adrenergic agonists and prostaglandin (PG) analogs.

The chronic nature of the disease makes patient compliance with multiple, additive therapies problematic. As described below, the next 20 years will see the development of new treatment strategies with longer duration of effect and increased efficacy that will decrease the role of the patient in the treatment equation and reduce adverse events.

\section{CYTOSKELETON MODULATION AND CONVENTIONAL OUTFLOW}

Studies of the role of the trabecular meshwork (TM) cytoskeleton in the regulation of aqueous humor outflow point to this system/ pathway as a promising target for glaucoma therapy. Altering the cytoskeleton/cell adhesion/cell contractility in the TM and ciliary muscle (CM) can enhance conventional outflow facility. Extracellular matrix (ECM) synthesis and degradation are ongoing processes that also influence resistance to fluid outflow.

Cell adhesions are dynamic and dependent on what is happening in the surrounding environment. They can vary in tightness and adhesivity. The interactions of structural proteins and signal transduction proteins affect the assembly and disassembly of the junctions, which are tied to the actin cytoskeleton and influenced by actomyosin contractility. ${ }^{1}$
Adhesion properties can be altered pharmacologically but also by physical forces such as stretch and shear stress. Understanding the regulation of the assembly and disassembly of actin microfilaments and how stress fibers and associated focal adhesions link the actin cytoskeleton to the ECM may lead to better ways of manipulating this system to advantage to enhance outflow.

Latrunculins are a type of actin disrupting molecule. They inhibit the assembly of actin by binding free actin in the cell, degrading the actin microfilaments, which loosens cell-cell junctions and causes cell rounding and separation. Topical administration of Latrunculin B results in lowered IOP but no change in AHF. ${ }^{2}$ Topical and intracameral administration increases outflow facility, suggesting disorganization of the actin cytoskeleton in the trabecular meshwork as the IOP lowering mechanism. ${ }^{3}$ The outflow facility effect following topical administration may not be evident for several hours. The cytoskeletal structures are weakened over time and outflow increases in response to the pressure gradient between the anterior chamber and Schlemm's canal, a situation that is more pronounced in the glaucomatous eye.

Micrographs of monkey eyes after intracameral exchange with Latrunculin B $(0.5 \mu \mathrm{M})$ show expansion of the juxtacanalicular area and separation of the inner wall endothelium of Schlemm's canal along with the first subendothelial cell layer, which results in a ballooning of the juxtacanalicular region. The meshwork is thus expanded, allowing fluid to pass through more easily. The inner wall, however, remains intact. ${ }^{4}$

$\mathrm{H}-7$ is a serine-threonine kinase inhibitor. It impedes actomyosin-driven contractility by inhibiting myosin light chain kinase or Rho kinase. ${ }^{5}$ Topical treatment in monkey eyes results in relaxation and elongation of Schlemm's canal inner wall endothelial cells, expansion of the juxtacanalicular meshwork and dilation of Schlemm's canal. ${ }^{6}$ In studies using gold tracer injected into the anterior chamber, H-7 treated eyes showed tracer spread throughout the inner wall while control eyes showed pockets of tracer resulting from fluid flow through 
specific pathways in the juxtacanalicular meshwork, demonstrating that cytoskeletal modulating compounds can expose the entire circumference of the inner wall of Schlemm's canal for fluid filtration. The effects of both $\mathrm{H}-7^{7}$ and Latrunculin $\mathrm{A}^{8}$ are reversible. This suggests that the effects are due to changes in cellular contractility and cytoskeletal organization rather than irreversible toxicity. Such compounds are now being tested in clinical trials.

\section{PROSTAGLANDINS AND UVEOSCLERAL OUTFLOW}

PGs are hormones that are synthesized, released, and act locally. Prostaglandin F (FP) receptors are G-protein-coupled receptors activated by prostaglandin- $\mathrm{F}_{2 \alpha}\left(\mathrm{PGF}_{2 \alpha}\right)$. FP receptors are found in the CM, TM and other tissues in the eye. The density of FP receptors in the CM is high compared to most other tissues in the body. ${ }^{9}$ Quantitative autoradiography, using the radioligand [3H]-BWA868C to examine localization of DP class prostaglandin receptors in human eye tissues, shows a high density of DP-receptors in the human ciliary epithelium/process, iris, choroid, longitudinal and circular CM, and retina. ${ }^{10}$

Topical treatment with various PG analogs lowers IOP mainly by increasing uveoscleral outflow $(\mathrm{Fu}){ }^{11-15}$ In monkeys eyes treated with PGF $_{2 \alpha}$ MMPs 1,2 , and 3 were increased in CM, iris root and sclera. ${ }^{16}$ Corresponding reductions were seen in collagen types I, III and IV. ${ }^{17}$ Treatment of CM cells in vitro with $\mathrm{PGF}_{2 \alpha}$ and analogs resulted in increased activity for MMP$1,2,3$, and 9 and decreased collagen in the media ${ }^{15}$ Morphologic studies showed that topical treatment of monkeys with $\mathrm{PGF}_{2 \alpha^{-}}$ isopropy ester induced a reduction in ECM in the widened spaces between ciliary smooth muscle fiber bundles. ${ }^{18}$ The reduction of ECM in the interbundle spaces of the CM and the sclera is largely responsible for the PG-mediated increase in uveoscleral outflow.

\section{DRUG DELIVERY}

One way of delivering therapeutic proteins to specific target tissues in the eye is via gene therapy. The aim in this strategy is to use an exogenous gene to reprogram target cells to make more or less of something, generating a product that is therapeutically useful, rather than trying to fix a defective gene. Targeting the TM with cytoskeletal disrupting genes can enhance outflow. ${ }^{19}$ Viral vector mediated expression of neurotrophic factors can promote retinal ganglion cell survival ${ }^{20}$ an effect that may be enhanced by combining gene and cellbased therapies. ${ }^{21}$

Methods of gene therapy include use of viral vectors, injection of naked plasmid DNA into tissue, liposome-mediated transfer, ultrasound and electroporation. ${ }^{22}$ Viral vectors are one of the most efficient delivery systems. Using replication deficient viral vectors incorporating green fluorescent protein (GFP) and appropriate promoters, long-term, TM targeted transgene expression has been achieved and monitored serially and noninvasively in monkeys and cats. ${ }^{23,24}$ Obstacles to gene therapy include inefficient gene transfer, difficulties localizing and delivering the genes to the appropriate target cells, duration of expression, viral toxicity and immune/inflammatory responses. ${ }^{22}$

Other drug delivery strategies include trans-scleral implants, intraocular delivery via anterior segment administration (uveoscleral outflow) or via posterior segment implantable devices which may be biological (cell based) or mechanical (polymer based).

Encapsulated cell technology (ECT) devices, inserted into the vitreous, are a way to achieve controlled, continuous and long-term administration of compounds to the eye. ECT implants contain cells that have been genetically modified to produce a specific therapeutic factor. The therapeutic protein that the encapsulated cells produce diffuses out of the implant and through the vitreous to the target site. Because they are encapsulated in a semipermeable hollow-fiber membrane, the cells have no direct contact with immune system cells. ECT is a unique combination of gene therapy, intravitreal release, and immuno-privilege technology, ${ }^{25}$ and is being tested in a phase 1 clinical trial, delivering ciliary neurotrophic factor (CNTF), to treat retinitis pigmentosa. ${ }^{26}$

\section{NEUROPROTECTION}

Glaucomatous optic neuropathy is progressive and results in neuronal death in the central visual pathway. Retinal ganglion cells (RGCs) and their axons are the primary targets for glaucoma neuroprotection. Axon damage and loss is likely due to multiple, interdependent factors. Receptor targets and pathways are being identified that could lead to the development of therapies to protect healthy but at risk RGCs and axons or rescue marginally damaged RGCs and axons within the central visual pathway. Optic nerve crush animal models using brain-derived neurotrophic factor (BDNF) demonstrate some increase in RGC survival. ${ }^{20}$ Although our understanding of axonal degeneration and death is increasing, there has been no proof of clinical efficacy for any neuroprotective compound in glaucoma. ${ }^{27,28}$

\section{STEM CELLS}

Evidence is emerging that adult stem cells are present in the adult human eye. ${ }^{29}$ This is an exciting discovery, raising the possibility that stem cells could be obtained from a patient with eye disease and used autologously, e.g. transplantation of stem cells to the TM in glaucomatous eyes might improve aqueous outflow. There is also evidence for a turnover of TM cells in the adult monkey eye in vivo, albeit at a very small level. This indicates that adult TM stem cells may exist in the primate eye, providing a model for stem cell studies.

Some of the main issues in stem cell transplantation include identification of the optimal precursor cell types, establishment 
of growth and differentiation conditions that meet safety and effectiveness standards, and the manipulation of the surrounding environment to allow transplanted cells to survive and function. ${ }^{30}$

\section{RISK FACTORS}

Elevated IOP remains the key risk factor for glaucomatous progression. As reported by the Early Manifest Glaucoma Trial Group (EMGT), the hazard ratio of progression increases by 11\% for each $1 \mathrm{mmHg}$ of higher IOP over a median follow-up time of 8 years. ${ }^{31}$ The Ocular Hypertension Treatment Study (OHTS) found a 9.5\% risk over 5 years to convert from ocular hypertension (OHT) to primary open angle glaucoma (POAG) if untreated. $^{32}$

Other risk factors for developing glaucoma are patient age, IOP, central corneal thickness, visual field pattern standard deviation and vertical cup-to-disc ratio. Several risk calculators have been developed using these factors. ${ }^{33,34} \mathrm{~A}$ risk model based on the OHTS findings was tested on data from the European Glaucoma Prevention Study (EGPS) placebo group, resulting in an estimated 5-year cumulative probability for developing POAG of $16.8 \%$. $^{35}$

While increased fluctuation of IOP was not reported as an independent factor for glaucoma progression in the EMGT, other studies, using different methods, found that diurnal IOP range and the IOP range over multiple days were significant, independent risk factors for progression. ${ }^{36,37}$ Longer lasting therapies minimize pressure spikes and reduce the pressure range as well as increase patient compliance. IOP range studies highlight that a single office visit IOP measurement may not indicate the extent of a patient's IOP fluctuation and risk of disease progression. 24 hour measurement of IOP in glaucoma patients shows that peak IOP and a larger fluctuation in IOP values is often found outside of office hours. ${ }^{38,39}$ Surgical, laser and pharmacologic treatment options are all effective at reducing mean IOP. They all flatten the diurnal IOP curve but there is no clear evidence that one is superior to the others in reducing fluctuations. ${ }^{40}$

\section{STRUCTURAL ASSESSMENT}

New imaging technologies are providing clinicians and researchers with more accurate ways of assessing structural change. Fourier domain (spectral) optical coherence tomography uses cross-sectional imaging with resolution sufficient to raise the possibility of directly assessing ganglion cell layers in the retina. Retinal nerve fiber layer (RNFL) imaging with scanning laser polarimetry (GDx VCC) may be useful in predicting progression of glaucoma. ${ }^{41}$ Confocal scanning laser ophthalmoscopy (cSLO) with the Heidelberg retinal tomograph
(HRT-3) offers detailed assessment of optic disc morphology and progression analysis software.

Another use of cSLO technology is imaging dying retinal ganglion cells (RGCs) in vivo. A technique has been developed using a fluorescent marker that lights up RGCs undergoing apoptosis (programmed cell death) in rats. ${ }^{42}$ More recently this same technique was used successfully in mice with the commercially available Heidelberg Retina Angiograph II. ${ }^{43}$ The ability to monitor disease progression and therapeutic efficacy at the RGC level could be invaluable.

\section{CONCLUSION}

The next 20 years will see significant developments in glaucoma therapy. Current therapeutic strategies will be modified and enhanced as knowledge of the pathways and mechanisms of aqueous humor dynamics increases. Each of these innovations and discoveries has the potential to play an important role in improving patient outcomes. Star Wars has landed, or is at least hovering.

\section{REFERENCES}

1. Geiger B, Bershadsky A, Pankov R, Yamada KM. Transmembrane crosstalk between the extracellular matrixcytoskeleton crosstalk. Nature Rev Mol Cell Biol 200;2:793805.

2. Peterson JA, Tian B, McLaren JW, et al. Latrunculin's effects on intraocular pressure, aqueous humor flow and corneal endothelium. Invest Ophthalmol Vis Sci 2000;41:1749-58.

3. Peterson JA, Tian B, Geiger B, Kaufman PL. Effect of latrunculinB on outflow facility in monkeys. Exp Eye Res 2000;70:30713.

4. Sabanay I, Tian B, Gabelt BT, Geiger B, Kaufman PL. Latrunculin B effects on aqueous outflow and trabecular meshwork and corneal endothelium structure in the monkey eye. Exp Eye Res 2006;82:236-46.

5. Volberg T, Geiger B, Citi S, Bershadsky AD. Effect of protein kinase inhibitor $\mathrm{H}-7$ on the contractility, integrity and membrane anchorage of the microfilament system. Cell Motility Cytoskel 1994;29:321-38.

6. Sabanay I, Gabelt BT, Tian B, Kaufman PL, Geiger B. H-7 effects on structure and fluid conductance of monkey trabecular meshwork. Arch Ophthalmol 2000;118:955-62.

7. Sabanay I, Tian B, Gabelt BT, Geiger B, Kaufman PL. Functional and structural reversibility of $\mathrm{H}-7$ effects on the conventional aqueous outflow pathway in monkeys. Exp Eye Res 2004;78:137-50.

8. Peterson JA, Tian B, Bershadsky AD, et al. Latrunculin-A increases outflow facility in the monkey. Invest Ophthalmol Vis Sci 1999;40:931-41. 
9. Ocklind A, Lake S, Wentzel P, Nistér M, Stjernschantz J. Localization of the prostaglandin $\mathrm{F}_{2 \alpha}$ receptor messenger RNA and protein in the cynomolgus monkey eye. Invest Ophthalmol Vis Sci 1996;37:716-26.

10. Sharif NA, Davis TL, Williams GW. Ocular hypotensive DPclass prostaglandin receptor affinities determined by quantitative autoradiography on human eye sections. J Ocul Pharmacol Ther 2005;21(2):121-32.

11. Nilsson SF, Sperber GO, Bill A. The effect of prostaglandin F2 alpha-1-isopropylester (PGF2 alpha-IE) on uveoscleral outflow. Prog Clin Biol Res 1989;312:429-36.

12. Crawford K, Kaufman PL. Pilocarpine antagonizes $\mathrm{PGF}_{2 \alpha^{-}}$ induced ocular hypotension: Evidence for enhancement of uveoscleral outflow by PGF $2 \alpha$. Arch Ophthalmol 1987;105:111216.

13. Gabelt BT, Kaufman PL. The effect of prostaglandin F2 alpha on trabecular outflow facility in cynomolgus monkeys. Exp Eye Res 1990;51(1):87-91.

14. Gabelt BT, Kaufman PL. The effect of prostaglandin $F_{2 \alpha}$ on trabecular outflow facility in cynomolgus monkeys. Exp Eye Res 1990;51:87-91.

15. Weinreb RN, Toris CB, Gabelt BT, Lindsey JD, Kaufman PL. Effects of prostaglandins on the aqueous humor outflow pathways. Surv Ophthalmol 2002;47 Suppl 1:S53-64.

16. Gaton DD, Sagara T, Lindsey JD, et al. Increased matrix metalloproteinases 1,2 , and 3 in the monkey uveoscleral outflow pathway after topical prostaglandin F(2 alpha)-isopropyl ester treatment. Arch Ophthalmol 2001;119(8):1165-70.

17. Sagara T, Gaton DD, Lindsey JD, et al. Topical prostaglandin F2alpha treatment reduces collagen types I, III, and IV in the monkey uveoscleral outflow pathway. Arch Ophthalmol 1999;117(6):794-801.

18. Tamm E, Lutjen-Drecoll E, Rohen JW. Age-related changes of the ciliary muscle in comparison with changes induced by treatment with prostaglandin F2 alpha. An ultrastructural study in rhesus and cynomolgus monkeys. Mech Ageing Dev 1990;51(2):101-20.

19. Liu X, Hu Y, Filla MS, et al. The effect of C3 transgene expression on actin and cellular adhesions in cultured human trabecular meshwork cells and on outflow facility in organ cultured monkey eyes. Mol Vis 2005;11:1112-21.

20. Martin KR, Quigley HA, Zack DJ, et al. Gene therapy with brain-derived neurotrophic factor as a protection: retinal ganglion cells in a rat glaucoma model. Invest Ophthalmol Vis Sci 2003;44(10):4357-65.

21. Leaver SG, Cui Q, Plant GW, et al. AAV-mediated expression of CNTF promotes long-term survival and regeneration of adult rat retinal ganglion cells. Gene Ther 2006;13(18);1328-41.

22. Liu X, Brandt CR, Rasmussen CA, Kaufman PL. Glaucoma gene therapy. Expert Rev Ophthalmol 2007;2:227-36.
23. Poeschla EM, Loewen N, Rasmussen C, et al. Transduction of nonhuman primate trabecular meshwork with lentiviral vectors. Invest Ophthalmol Vis Sci 2006;47(ARVO Abnr 2696).

24. Loewen N, Fautsch MP, Teo WL, et al. Long-term, targeted genetic modification of the aqueous humor outflow tract coupled with noninvasive imaging of gene expression in vivo. Invest Ophthalmol Vis Sci 2004;45(9):3091-8.

25. Tao W. Application of encapsulated cell technology for retinal degenerative diseases. Expert Opin Biol Ther 2006;6(7):717-26.

26. Sieving PA, Caruso RC, Tao W, et al. Ciliary neurotrophic factor (CNTF) for human retinal degeneration: phase I trial of CNTF delivered by encapsulated cell intraocular implants. Proc Natl Acad Sci U S A, 2006;103(10):3896-901.

27. Levin LA. Axonal loss and neuroprotection in optic neuropathies. Can J Ophthalmol 2007;42(3):403-8.

28. Weinreb RN. Glaucoma neuroprotection: What is it? Why is it needed? Can J Ophthalmol 2007;42(3):396-8.

29. Limb GA, Daniels JT, Cambrey AD, et al. Current prospects for adult stem cell-based therapies in ocular repair and regeneration. Curr Eye Res 2006;31(5):381-90.

30. Levin LA, Ritch R, Richards JE, Borras T. Stem cell therapy for ocular disorders. Arch Ophthalmol 2004;122(4):621-7.

31. Bengtsson B, Leske MC, Hyman L, Heijl A. Fluctuation of intraocular pressure and glaucoma progression in the early manifest glaucoma trial. Ophthalmology 2007;114(2):205-9.

32. Kass MA, Heuer DK, Higginbotham EJ, et al. The Ocular Hypertension Treatment Study: a randomized trial determines that topical ocular hypotensive medication delays or prevents the onset of primary open-angle glaucoma. Arch Ophthalmol 2002;120(6):701-13; discussion 829-30.

33. Medeiros FA, Weinreb RN, Sample PA, et al. Validation of a predictive model to estimate the risk of conversion from ocular hypertension to glaucoma. Arch Ophthalmol 2005; 123(10):1351-60.

34. Mansberger SL, Cioffi GA. The probability of glaucoma from ocular hypertension determined by ophthalmologists in comparison to a risk calculator. J Glaucoma 2006;15(5):426-31.

35. Gordon MO, Torri V, Miglior S, et al. Validated prediction model for the development of primary open-angle glaucoma in individuals with ocular hypertension. Ophthalmology 2007;114(1):10-9.

36. Asrani S, Zeimer R, Wilensky J, et al. Large diurnal fluctuations in intraocular pressure are an independent risk factor in patients with glaucoma. J Glaucoma 2000;9(2):134-42.

37. Nouri-Mahdavi K, Hoffman D, Coleman AL, et al. Predictive factors for glaucomatous visual field progression in the Advanced Glaucoma Intervention Study. Ophthalmology 2004;111(9): 1627-35.

38. Hughes E, Spry P, Diamond J. 24-hour monitoring of intraocular pressure in glaucoma management: a retrospective review. J Glaucoma 2003;12(3):232-6. 
39. Barkana Y, Anis S, Liebmann J, Tello C, Ritch R. Clinical utility of intraocular pressure monitoring outside of normal office hours in patients with glaucoma. Arch Ophthalmol 2006;124(6):7937.

40. Wilensky JT. The role of diurnal pressure measurements in the management of open angle glaucoma. Curr Opin Ophthalmol 2004;15(2): 90-2.

41. Mohammadi K, Bowd C, Weinreb RN, et al. Retinal nerve fiber layer thickness measurements with scanning laser polarimetry predict glaucomatous visual field loss. Am J Ophthalmol 2004;138(4):592-601.

42. Cordeiro MF, Guo L, Luong V, et al. Real-time imaging of single nerve cell apoptosis in retinal neurodegeneration. Proc Natl Acad Sci USA 2004;101(36):13352-6.

43. Maass A, von Leithner PL, Luong V, et al. Assessment of rat and mouse RGC apoptosis imaging in vivo with different scanning laser ophthalmoscopes. Curr Eye Res 2007;32(10):85161.

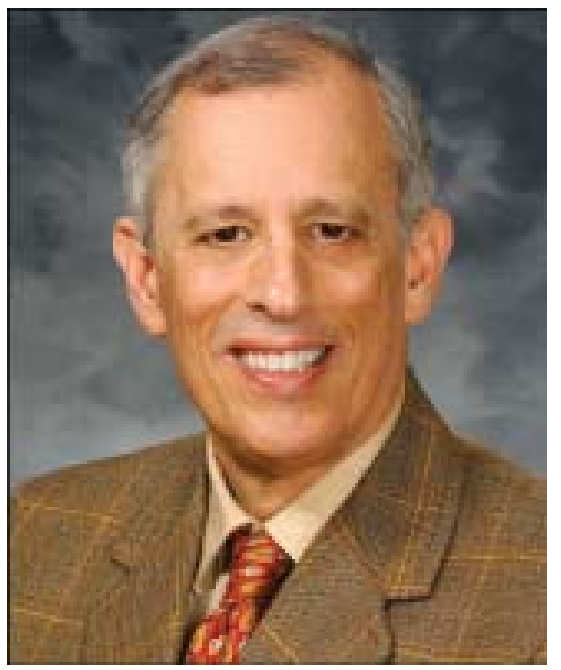

Dr Paul L Kaufman

(kaufmanp@mhub.ophth.wisc.edu)

Kind words can be short and easy to speak, but their echoes are truly endless. 